\title{
AS PRÁTICAS DE TRADUÇÃO REDEFINIDAS PELAS RELAÇÕES LINGUÍSTICAS NA ECONOMIA INFORMACIONAL
}

\author{
TRANSLATION PRACTICES REDEFINED BY LINGUISTIC \\ RELATIONS IN THE INFORMATIONAL ECONOMY
}

\section{Érika Nogueira de Andrade Stupiello*}

\section{RESUMO}

Este trabalho tem por objetivo apresentar um panorama das relações linguísticas no mundo globalizado via internet, refletindo sobre a crescente ruptura da associação entre língua e cultura e sua influência para a prática de tradução na contemporaneidade. A partir da descrição das principais mudanças na contratação da tradução na atualidade, discute-se como a preferência pela padronização da língua de origem, especialmente o inglês, dos materiais textuais em formato eletrônico colabora para a manutenção dessa língua em sua "posição dominante" ao mesmo tempo em que desloca o ônus da tradução para aqueles que não a conhecem. Conforme argumento, é essa língua híbrida e sem vínculo com sua cultura de origem que, na maioria das vezes, serve de ponto de partida para a tradução de materiais textuais para as mais diversas línguas e posterior divulgação em meio eletrônico.

Palavras-chave: internet; tradução; memórias de tradução.

\section{ABSTRACT}

The purpose of this paper is to present an overview of the linguistic relations in the globalized world via internet, considering the growing dissociation between language and culture and its influence on the contemporary practice of translation. From the description of the main changes in the way translation services are currently hired, we discuss how the preference for standardization of the original language, mainly English, of textual materials in electronic format collaborates in maintaining this language at its "dominant position", whereas it dislocates the burden of translation to those who cannot speak it. As we argue, this "hybrid" language with no ties to its original culture is mostly used as a source for the translation of textual materials into different languages and subsequent dissemination in

\footnotetext{
*. UNESP, São José do Rio Preto (SP), Brasil. erika@traducao-interpretacao.com.br
} 
electronic medium.

Keywords: internet; translation; translation memories.

\section{INTRODUÇÃO}

Os rumos conferidos nas últimas três décadas à economia mundial com o desenvolvimento das tecnologias de informação que, idealmente, proveriam meios para a comunicação e o comércio sem fronteiras, têm influência direta no aumento dos intercâmbios linguísticos entre povos de diferentes nações. A instantaneidade com que mensagens, textos e documentos de naturezas diversas viajam pela internet e são difundidos eletronicamente em diversas partes do mundo exige, cada vez mais, que o conhecimento produzido possa ser entendido e processado em diferentes línguas com rapidez semelhante à da sua produção.

Essa expansão da disseminação da informação pela internet impôs novas exigências à prática de tradução, tanto com relação ao crescimento de sua necessidade quanto à diminuição de seu tempo de produção. Segundo a ordem mercadológica atual, o comércio internacional é preferencialmente concretizado se as informações na língua de origem forem oferecidas nas línguas traduzidas concomitantemente ao lançamento do produto. A fim de atenderem principalmente à demanda de urgência de seus serviços e manterem-se competitivos, tradutores que prestam serviços para esse segmento, cada vez mais, estão lançando mão das ferramentas tecnológicas de auxílio à tradução, em especial, os sistemas de memórias de tradução.

Em linhas gerais, os sistemas de memórias constituem ferramentas de auxílio à tradução que permitem recuperar e reaproveitar segmentos de trabalhos realizados e armazenados por esses sistemas paralelamente a seus respectivos originais. De acordo com a literatura da área (especialmente AUSTERMÜHL, 2001; BOWKER, 2002), o emprego desses sistemas constituiria um recurso de grande auxílio na manutenção da padronização terminológica, podendo resultar em economia de tempo em trabalhos muito extensos e desenvolvidos em equipe.

Este trabalho reflete sobre as relações linguísticas no mundo globalizado via internet e suas influências para a prática de tradução na contemporaneidade. Com base na descrição das principais mudanças no modo como a tradução é contratada e na apresentação de algumas das exigências de produção impostas pelo atual ritmo econômico, procura-se justificar a implementação de ferramentas, como os sistemas de memórias de tradução, adotados pelo tradutor para suprir a grande demanda por trabalhos concluídos em prazos cada vez menores. 


\section{TRADUZINDO 0 "INGLÊS GLOBAL": ALGUMAS CONSIDERAÇÕES SOBRE AS TECNOLOGIAS DE INFORMAÇÃO CONTEMPORÂNEAS E SUAS RELAÇÕES COM A TRADUÇÃO}

O imperativo de uma resposta rápida às informações em circulação via internet parece favorecer a adoção de uma ou poucas línguas como meios de expressão global, ainda que os emissores e receptores envolvidos na comunicação não sejam falantes nativos dela. Em um mundo em que convivem cerca de 2.500 a 3.000 línguas, a língua inglesa é, com frequência, identificada como língua da globalização, seguida por outras línguas também consideradas dominantes nos planos políticoeconômico e tecnológico, como o francês, o espanhol e, na atualidade, o chinês (WODAK, 2004). As estatísticas que demonstram o domínio do inglês, por outro lado, não fazem referência à maneira como se distribuem os falantes dessa língua e nem ao modo como ela é usada, mas, ao contrário, sugerem haver uma língua inglesa homogênea e consequente da hegemonia global estadunidense.

Um estudo que acompanha a evolução das línguas na internet desde 1998, desenvolvido pela Direção de Terminologia e Indústrias da Língua (DTIL), órgão filiado à União Latina e que se ocupa em promover a difusão das línguas latinas nas infovias, revela o domínio do inglês nas páginas eletrônicas indexadas por diferentes motores de busca da internet. Conforme demonstra uma das tabelas que reúne dados relativos aos anos em que foi conduzida a pesquisa, a língua inglesa vem mantendo, ao longo dos anos, uma posição bastante privilegiada em relação às demais línguas latinas contempladas pelo estudo:

Tabela 1 - Evolução das línguas nas páginas da internet entre 1998 e 2007. Disponível em: <http://ditl.unilat.org/LI/2007/resultados_fr.htm>. Acesso em: 2 ago. 2008.

$\begin{array}{lcccccccc}\text { Páginas da web } & 1998 & 2000 & 2001 & 2002 & 2003 & 2004 & 2005 & 2007 \\ \text { em } & & & & & & & & \\ \text { INGLÊS } & 75 \% & 60 \% & 52 \% & 50 \% & 49 \% & 45 \% & 45 \% & 45 \% \\ \text { ESPANHOL } & 2,53 \% & 4,79 \% & 5,50 \% & 5,80 \% & 5,31 \% & 4,08 \% & 4,60 \% & 3,80 \% \\ \text { FRANCÊS } & 2,81 \% & 4,18 \% & 4,45 \% & 4,80 \% & 4,32 \% & 4,00 \% & 4,95 \% & 4,41 \% \\ \text { PORTUGUÊS } & 0,82 \% & 2,25 \% & 2,55 \% & 2,81 \% & 2,23 \% & 2,36 \% & 1,87 \% & 1,39 \% \\ \text { ITALIANO } & 1,50 \% & 2,62 \% & 3,08 \% & 3,26 \% & 2,59 \% & 2,66 \% & 3,05 \% & 2,66 \% \\ \text { ROMENO } & 0,15 \% & 0,21 \% & 0,18 \% & 0,17 \% & 0,11 \% & 0,11 \% & 0,17 \% & 0,28 \% \\ \text { ALEMÃO } & 3,75 \% & 2,85 \% & 6,75 \% & 7,21 \% & 6,80 \% & 7,13 \% & 6,94 \% & 5,90 \% \\ \text { CATALÃO } & & & & & & & & 0,14 \% \\ \text { DEMAIS } & 13,44 \% & 22,20 \% & 23,68 \% & 25,97 \% & 29,65 \% & 31,32 \% & 33,43 \% & 36,54 \%\end{array}$

Observa-se que a queda apresentada no número de páginas em inglês ao longo dos anos do estudo é gradativa até estacionar-se, a partir de 2004. Em 
comparação ao ano inicial da pesquisa, o declínio do inglês é compensado pelo aumento da presença de outras línguas na rede, especialmente línguas asiáticas (que se encaixam na categoria "demais") e não pela ampliação da participação das línguas latinas pesquisadas. A primazia da língua inglesa mantém-se e, como meio de propagação das inovações tecnológicas, a internet seria um local favorável à implementação de uma "geopolítica do inglês" na atualidade. Essa constatação pode ser verificada principalmente pelo fato de um crescente número de empresas que hospedam páginas eletrônicas na internet, em sua maioria outrora monolíngues, estarem buscando serviços de tradução para se tornarem bilíngues ou multilíngues, quase sempre com o inglês entre as línguas oferecidas para acesso à página. Se, no passado, a rivalidade de poderes e influências direcionava-se à conquista de territórios, no presente, é possível afirmar que essa luta pelo domínio econômico e, até, cultural, realiza-se no dinâmico plano da comunicação eletrônica.

Conforme defende Rajagopalan (2005, p. 147), não se pode ingenuamente acreditar que o domínio linguístico do inglês teria se concretizado a partir de uma escolha, em escala mundial, por uma língua para possibilitar a comunicação entre povos de diferentes nações. O favorecimento à adoção da língua inglesa realizouse na mesma proporção em que "países anglófonos, notadamente os Estados Unidos, passaram a gozar de poder hegemônico no mundo pós-Segunda Grande Guerra". A ascensão econômica estadunidense no cenário do pós-guerra tornou o inglês proeminente nas inovações tecnológicas oriundas daquele país, assim como nas descobertas científicas e médicas. Em organismos internacionais como a Organização das Nações Unidas, o inglês também desempenha papel principal entre as línguas de trabalho.

Essa posição privilegiada da língua inglesa tem também motivos políticos, sendo verificada até mesmo no continente europeu, local em que a diversidade cultural e a pluralidade linguística são assuntos constantes de debates políticos a favor da comunicação e integração intercultural (WODAK, 2004). No caso da União Européia, o problema da pluralidade linguística é tratado como uma questão tanto política como técnica. Segundo o relato de Calvet (2007), quando a França assumiu a presidência da União Européia em 1994, uma das primeiras propostas do então ministro francês de Assuntos Europeus foi a de limitar a cinco o número de línguas de trabalho da comunidade, naquela época composta por quinze países membros. A campanha francesa propunha a adoção do inglês, do francês, do alemão, do espanhol e do italiano, uma escolha que, para Calvet (2007, p. 134), "enfatiza a comunicação no seio da Europa, excluindo na mesma tacada o português, muito mais falado no mundo que o italiano, o alemão e até mesmo o francês". A principal preocupação da proposta não era, como a França desejava transparecer, estabelecer 
as línguas de trabalho com base em dados estatísticos europeus (número de falantes dessas línguas no continente), mas evitar que o inglês se tornasse "a única língua de trabalho da União Europeia".

De fato, o domínio da língua inglesa estende-se muito além do continente europeu. Segundo dados apresentados por Rajagopalan, um quarto da população mundial possui algum conhecimento dessa língua ou condições de lidar com ela. Quando se trata da divulgação do conhecimento científico, a esfera de ação do inglês chega a 80 a $90 \%$ da produção mundial. Todavia, não é possível afirmar que o inglês da comunicação mundial corresponderia à língua como conhecida nos países que a têm como língua nativa, pois, como explica o pesquisador,

a língua inglesa que circula no mundo, que serve como meio de comunicação entre os diferentes povos do mundo de hoje, não pode ser confundida com a língua que se fala nos Estados Unidos, no Reino Unido, na Austrália, ou onde quer que seja. A língua inglesa, tal qual vai se expandindo no mundo inteiro (a que chamo de World English) é um fenômeno linguístico sui generis, pois, segundo as estimativas, nada menos que dois terços dos usuários desse fenômeno linguístico são aqueles que, segundo os nossos critérios antigos e ultrapassados, seriam considerados não-nativos. (RAJAGOPALAN, 2005, p.151)

Para Rajagopalan (2005, p. 153), o inglês do mundo globalizado constituiria uma nova língua (o World English) que, conforme afirma, teria perdido seu "vínculo com a cultura anglo-saxã", na medida em que adotada na comunicação entre pessoas das mais diversas culturas e com as mais variadas formações ideológicas. Essa língua, elevada à condição de "língua franca", há muito teria se libertado do domínio e controle exercidos pela "metrópole", uma referência aos países anglo-americanos, que se consideram proprietários e guardiões dessa língua, concebendo-a como mais "uma preciosa commodity" a ser valorizada e comercializada.

Um espaço revelador do domínio do inglês e de sua incorporação a outras línguas pode ser constatado na rede mundial de computadores. Segundo Jean-Marie Le Breton (2005), a internet constituiria o "campo digital" e revelador da potência do domínio da língua inglesa, não somente em termos de volume, mas, em especial, de ascensão social e prestígio. Como explica o autor,

não se trata de ocupar totalmente esse campo, mas uma espécie de vácuo favorece o uso do inglês: quanto mais difusão, melhor imagem. O inglês lança suas redes muito além do que a geografia ensina. Numerosos países industrializados, cuja capacidade de inovação é imensa e cuja língua é vigorosa, não deixam de pagar um tributo notável ao inglês, em consequência das posições conquistadas na abertura do mercado. (LE BRETON, 2005, p. 23) 
O "tributo" prestado ao inglês e ao qual Le Breton alude envolve os setores da inovação tecnológica, de comunicação e de informação, áreas em crescente expansão em que o inglês atua como língua veicular. Conhecer e utilizar a língua inglesa nesses setores pode significar promoção profissional, social e econômica. Para Le Breton, "tudo ocorre como se 'pensar em inglês' se tornasse necessário para entender o mundo" (LE BRETON, 2005, p. 23).

A língua supostamente capaz de moldar a compreensão do mundo contemporâneo não seria, como suposto com frequência, patrimônio exclusivo das nações anglo-americanas. Ela também não seria exclusivamente controlada pelos povos que a têm como língua materna. Em um estudo elaborado para o Conselho Britânico sobre a posição do inglês no mundo contemporâneo, David Graddol (2006, p. 19) apresenta dados que sugerem que "o inglês não está mais sendo aprendido como língua estrangeira em reconhecimento ao poder hegemônico dos falantes nativos de inglês". As pesquisas apresentadas por esse linguista exploram a complexidade das relações entre a língua inglesa e as línguas dos países com participação ativa na economia globalizada, em especial a China e a Índia que, conforme defende, "detêm a chave para o futuro a longo prazo do inglês como língua global" (GRADDOL, 2006, p. 15).

A obra de Graddol (2006), intitulada English Next, reflete em sua composição a natureza de grande parte da comunicação atual, especialmente ao se apresentar em formato eletrônico para acesso e leitura gratuitos pela internet. A reflexão que desenvolve nesse trabalho baseia-se em pesquisas feitas para um estudo anteriormente publicado - The Future of English?, que tiveram como meta produzir conhecimento para "facilitar o debate informado sobre o futuro do uso e da aprendizagem da língua inglesa no mundo" (GRADDOL, 1997, p. 66).

Em 1997, Graddol relacionou a supremacia da língua inglesa no âmbito da rede mundial de computadores ao fato de, até então, 90\% dos provedores estarem sediados em países falantes dessa língua. Essa configuração, todavia, logo começaria a ser alterada com o desenvolvimento de bases de usuários e provedores no continente asiático, assim como pela criação de programas de software e de novos navegadores e padrões de HTML (que controlam a língua em que as páginas eletrônicas são escritas), que passaram a oferecer condições para acesso em diversas línguas. Essas mudanças teriam tido impacto direto no domínio do inglês na internet e, como entrevê Graddol:

a quantidade de materiais na internet em línguas que não sejam o inglês deve expandir de maneira dramática na próxima década. $\mathrm{O}$ inglês continuará preeminente por algum tempo, mas acabará se tornando uma língua entre muitas. É, portanto, um engano insinuar que o 
inglês é, de alguma forma, a língua nativa da internet. Ele será usado no ciberespaço da mesma forma que é empregado em outros lugares: em fóruns internacionais, para a disseminação do conhecimento científico e técnico, na publicidade, para a promoção de bens de consumo e para serviços pós-venda. (GRADDOL, 1997, p. 61)

A principal argumentação dos dois trabalhos desenvolvidos por esse pesquisador assenta-se sobre a tese de que a ascensão do que denomina "inglês global" não representa o "triunfo dos falantes nativos", pois, como sustenta, "a realidade é que existem mudanças muito maiores e mais complexas agora acontecendo no sistema linguístico mundial. $\mathrm{O}$ inglês não é a única 'grande' língua no mundo e sua posição como língua global está agora aos cuidados de falantes multilíngues" (GRADDOL, 2006, p. 57).

Em English Next, Graddol (2006) divulga resultados de pesquisas desenvolvidas por institutos especializados que indicam que a proporção de usuários da internet que têm o inglês como língua materna está diminuindo, assim como o número de páginas eletrônicas exclusivamente compostas nessa língua. A sistemática de pesquisa adotada difere dos resultados do levantamento elaborado pela DTIL, anteriormente apresentados neste trabalho. Embora proporcionalmente o inglês ainda ocupe uma posição privilegiada em relação à situação de outras línguas faladas por usuários da internet (como atestado pela pesquisa da DTIL), Graddol argumenta que o acesso a sites em inglês diminui à medida que páginas são traduzidas e disponibilizadas na primeira língua desses usuários.

Páginas eletrônicas da internet constituem um exemplo dos tipos de materiais com que lidam os tradutores na contemporaneidade e que, de muitas maneiras, têm influenciado a maneira como a tradução é praticada. Algumas das mudanças vivenciadas na prática devem-se às características dos materiais textuais eletrônicos a serem traduzidos, assim como à maneira como esses serviços são contratados e, até, realizados.

No ensaio "Technology and Translation", Biau Gil e Pym (2006) discutem algumas das mudanças vividas pelo tradutor em seu trabalho como resultado dos avanços tecnológicos e do processo de globalização. A mais importante delas, segundo os autores, seria o próprio formato dos textos a serem traduzidos, em sua maioria em meio eletrônico, sem delimitação de início ou fim e em constante processo de atualização. Para esses teóricos, a tradução, na contemporaneidade, "torna-se mais um trabalho com banco de dados, glossários, e uma série de ferramentas eletrônicas, no lugar de textos de origem completos e definitivos" (BIAU GIL; PYM, 2006, p. 6). Entre as ferramentas mencionadas pelos autores estariam os dicionários e glossários eletrônicos, a própria internet (como instrumento 
de pesquisa), os programas de tradução automática e os sistemas de memórias de tradução.

Essas ferramentas seriam representativas dos avanços tecnológicos no campo da tradução e de mudanças na maneira como clientes e tradutores se comunicam (internet) e no modo como produções anteriores do tradutor são recuperadas e reaproveitadas (por meio de bancos de dados terminológicos e fraseológicos).

Reconhecida como um meio para a comunicação sem fronteiras, a internet suprimiu a distância que separava o tradutor dos grandes centros comerciais e industriais, onde a demanda por tradução sempre se mostrou significativa e, anteriormente à era digital, acabava sendo atendida com bastante dificuldade e demora quase exclusivamente por tradutores que atuavam nas proximidades dos grandes mercados de trabalho. Para Biau Gil e Pym, o tradutor contemporâneo, munido de conexão à internet e ferramentas eletrônicas, estaria apto a prestar serviços para clientes em qualquer parte do mundo, mediante cadastramento em diferentes agências de tradução disponíveis on-line e que se ocupam de estabelecer conexões entre a oferta de tradutores nas mais diferentes áreas e a demanda por traduções em diversas especializações.

A proximidade virtual entre tradutor e cliente, todavia, seria limitada e, muitas vezes, incapaz de assegurar a relação de confiança que governa a contratação de um trabalho e, mesmo em uma era em que muitos dos relacionamentos se dão via teclado e por um clique de um mouse, não seria possível dizer o mesmo em relação à tradução, pois, como explicam Biau Gil e Pym,

a tradução é ainda um serviço que depende de um alto grau de confiança entre o tradutor e o cliente. Poucos dos trabalhos com alta remuneração vêm de clientes jamais vistos; os honorários pagos em países diferentes variam bastante; os melhores contatos ainda são provavelmente aqueles feitos face a face ou por indicação. (BIAU GIL; PYM, 2006, p. 7) ${ }^{1}$

A mobilidade extraterritorial proporcionada pela internet apresenta também limitações. Na atualidade, frequentemente, atrela-se a qualidade tradutória à possibilidade de a tradução ser realizada no país da língua alvo. Outro fator que influencia a procura por um tradutor seria a conhecida lei da oferta, a qual a internet também teria se encarregado de tornar abundante e, por esse motivo, nem sempre favorável à remuneração do tradutor. Para Bert Esselink, diretor de uma empresa europeia de consultoria de serviços de globalização,

1. Esta e as demais traduções de citações em língua estrangeira foram feitas por mim. 
a qualidade de um texto, traduzido no país da língua alvo, é, em geral, mais alta e o preço muitas vezes sensivelmente mais baixo. Experimente solicitar um orçamento de tradução do holandês para o mandarim na Holanda e na China e entenderá o que quero dizer. A internet possibilitou o rompimento dessas barreiras. Via internet, é igualmente rápido e barato enviar documentos para tradução tanto para o local mais remoto do planeta quanto para o escritório vizinho. (ESSELINK, 2001, apud CRONIN, 2006, p. 46)

Esselink assenta sua convicção de obter uma tradução "de alta qualidade" no dinamismo da produção tradutória pela capacidade de recuperação de significados já estabelecidos no texto de origem e que, traduzidos para as línguas de interesse, seriam naturalmente aceitos e válidos em contextos culturais diversos. Por esse ponto de vista, a figura do tradutor seria considerada mais a de um "propagador" de significados de uma língua para outra(s). Ao se focar no vencimento da barreira da distância e na valoração da relação custo-benefício na contratação de uma tradução, Essselink privilegia a obtenção do produto final e a receptividade que este poderá ganhar nos países para os quais será produzido.

Estando a atenção voltada para o produto final, considerar a mediação do tradutor como parte do processo parece ir contra o fluxo urgente de transmissão de informações e de comunicação, em que são valorizadas trocas rápidas e presumidamente diretas. Conforme constata Cronin,

de fato, a tendência em um mundo de compressão tempo-espaço é favorecer intercâmbios de primeira ordem em vez daqueles de segunda ordem, isto é, transações rápidas limitadas em tempo e envolvendo contato limitado em vez de compromissos mais longos, multidimensionais e complexos. (CRONIN, 2003, p. 49)

A comunicação contemporânea, de acordo com Cronin, valorizaria "transações rápidas e de tempo limitado" e não mais compromissos duradouros, os quais caracterizariam os "intercâmbios de segunda-ordem" mencionados. Conforme argumenta, a pressão exagerada que a tecnologia da informação exerce sobre o modo como nos comunicamos faz com que a atenção seja deslocada do processo para o produto e não se consideram os desafios e o tempo que se impõem para que o tradutor construa a comunicação em outra língua. Nesse meio de comunicação composto por diversidades culturais e linguísticas que se aproximam somente no plano virtual, a tradução figura, concomitantemente, como uma necessidade e uma lembrança da impossibilidade de se anular a pluralidade de línguas e culturas.

A presença do tradutor como mediador da tradução faz desta um trabalho incômodo, porém indispensável para possibilitar a comunicação e a compreensão entre usuários-falantes de diferentes línguas que, idealmente, deveriam realizar- 
se de maneira direta e neutra. A irrealizabilidade dessa condição faz com que o tradutor ocupe uma posição paradoxal no mundo da globalização, na qual

parte de seu papel profissional é precisamente facilitar a proliferação de intercâmbios de primeira-ordem, em que uma pessoa não é obrigada a passar anos aprendendo uma língua para realizar negócios no exterior por causa da presença do tradutor e do intérprete, e, entretanto, os próprios tradutores são definidos por seu compromisso vitalício com intercâmbios de segunda ordem. (CRONIN, 2003, p. 49)

A intervenção da interpretação do tradutor, inseparável de seu trabalho de construção da comunicação entre falantes de línguas diferentes, opõe-se à tendência mundial, que valoriza o acesso imediato ao conteúdo de um enunciado. A exigência da tradução permeando o esforço para alcançar o Outro é uma constante lembrança de que, embora pessoas possam aparentar estar mais próximas graças às conquistas no setor da tecnologia da comunicação, elas ainda permanecem afastadas pela distância cultural e pela diversidade linguística.

Por outro ângulo, quando admitimos a posição privilegiada que a língua inglesa ainda ocupa em relação às demais línguas envolvidas no processo da globalização, necessariamente temos que considerar o papel que a tradução desempenha nos vários sentidos em que ela se realiza (língua inglesa para as demais línguas, demais línguas para língua inglesa e tradução entre as diversas línguas) para promover a comunicação entre falantes de diferentes línguas. Como explica Cronin (2003, p. 61), "a era global não significa somente um aumento em tradução de uma língua dominante. Significa também um aumento significativo e constante de tradução entre línguas".

A constatação de Cronin é corroborada por outro estudo de Graddol (2003) intitulado The Decline of the Native Speaker, em que são apresentados dados sobre a crescente e acentuada diminuição da população mundial considerada falante de inglês como língua nativa e o crescimento populacional em locais em que o inglês não é falado como primeira língua. Essas mudanças na distribuição de falantes de inglês não significa, como explica Graddol, que essa língua deixará de ocupar uma posição influente na comunicação global, pois,

o evidente declínio na posição de falantes nativos de inglês não é precursor da diminuição da importância da língua inglesa. O status futuro do inglês será menos determinado pelo número e pelo poder econômico de seus falantes nativos do que pelas tendências no uso do inglês como segunda língua. (GRADDOL, 2003, p. 157) 
As "tendências" a que Graddol se refere dizem respeito ao deslocamento, observado em seus estudos, em direção à adoção do inglês como língua da comunicação, tanto em países europeus como não-europeus, um ato sintomático do aumento do bilinguismo e do multilinguismo e da renúncia à ideia de que o uso do inglês teria como consequência o abandono das línguas maternas de cada país.

Oinglês, ou "ingleses", que figura comolíngua franca nocenário contemporâneo globalizado paga o preço do "hibridismo inevitável" (RAJAGOPALAN, 2005, p. 155) que o acomete, ao mesmo tempo em que se traduz para outras línguas a um ritmo que se tornou típico da era comunicação virtual. $\mathrm{O}$ atendimento às exigências de prazo e custo desse mercado depende, na contemporaneidade, de investimentos no desenvolvimento e da adoção por tradutores das ferramentas de auxílio à tradução, como sistemas de memórias de tradução, especialmente para trabalhos para a indústria de localização.

\section{SISTEMAS DE MEMÓRIAS DE TRADUÇÃO COMO INSTRUMENTAL PARA A RECUPERAÇÃO TRADUTÓRIA}

A automação, ainda que parcial, do trabalho de tradução é um condicionante para atuação desse profissional em projetos envolvendo textos de grande extensão (como a tradução de manuais) e em segmentos como a indústria de localização. A expansão da tradução nesses setores tem sido possibilitada, em especial, pelo emprego de meios que permitam ao tradutor concluir o trabalho de maneira rápida e, simultaneamente, gerar bancos de dados terminológicos e fraseológicos passíveis de reaproveitamento em trabalhos posteriores.

O reaproveitamento de traduções passadas como ferramenta para o início de um novo trabalho é o principal atributo dos sistemas de memórias, divulgado na literatura como uma forma de "alavancagem" de um novo trabalho de tradução, conforme alusão de Bowker (2002), que assim justifica a vantagem do uso das memórias de tradução:

embora a língua seja dinâmica, é bastante repetitiva, e as pessoas frequentemente utilizam expressões iguais ou semelhantes para comunicar ideias parecidas. O volume de tradução está crescendo e a maioria dos tradutores já passou pela experiência de ser contratado para traduzir um texto contendo passagens que eles (ou seus colegas) já traduziram em ocasiões anteriores. (BOWKER, 2002, p. 93, grifos meus)

A pressuposição de um grau considerável de repetições no texto de origem, bem como a recorrência de expressões e frases em trabalhos posteriores de uma 
mesma área, constituiria, para Bowker e conforme a literatura da área, o principal atrativo dos sistemas de memória. Segundo esse pensamento, os sistemas de memórias de tradução representariam um avanço na maneira como os tradutores aproveitam trabalhos anteriores que, no passado, eram muitas vezes armazenados em diversos arquivos e sem critérios definidos, o que dificultava sua recuperação e reutilização. Mesmo com os recursos de arquivos eletrônicos, a busca por traduções anteriores, conjugadas com seus respectivos originais, poderia ser desestimulante ao tradutor por tomar demasiado tempo, fazendo com que este optasse, na maioria das vezes, por elaborar uma tradução sem uma consulta aproveitável a trabalhos anteriores.

A certeza de uma reocorrência organizada de expressões "iguais" ou "repetidas" faz-se como grande promessa ao consequente aumento de desempenho que os sistemas de memórias de tradução alegam proporcionar. À primeira vista, a possibilidade de reaproveitamento de traduções anteriores pode ser bastante animadora, tanto para clientes como para os próprios tradutores. Por parte das empresas que necessitam de grandes volumes de tradução, a urgência de redução de custos exerce grande pressão para o emprego dos sistemas de memória, uma vez que se espera que a produção de uma tradução almeje também munir o banco de dados com mais segmentos pareados para aproveitamento posterior.

Em trabalhos de tradução executados com auxílio de memórias, duas práticas podem ser consideradas comuns para a compilação de bancos de dados de palavras e segmentos pareados a partir do texto original e da tradução, ambas com seus desdobramentos. A primeira ocorre quando o cliente fornece um banco de dados com termos, frases e expressões de traduções anteriores armazenados no decorrer de outros trabalhos, muitas vezes realizados por diversos tradutores. A segunda sucede quando tradutores compartilham entre si suas memórias, em um esforço integrado e convencionado entre eles para incrementar seus bancos de dados e ganhar competitividade em relação à maciça quantidade de dados terminológicos acumulados pelas agências de tradução e localização.

O emprego do banco de dados, provindo de quem contrata uma tradução, pode gerar conflitos porque, na maioria das vezes, os segmentos reaproveitados da memória do cliente não são remunerados, pois se acredita que a tarefa do tradutor restringe-se a localizar e transferir essas opções armazenadas e inseri-las na tradução. Conforme revela Weininger (2004),

o tradutor não recebe nada para a revisão e adaptação do material encontrado apesar de ser muitas vezes bastante necessária, principalmente por dois fatores: a) o segmento idêntico no nível de frase provém de outro contexto, e b) há erros de todos os níveis (ortográficos, sintáticos, semânticos, terminológicos). (WEININGER, 2004, p. 255) 
O não pagamento do tradutor por ocorrências recuperadas da memória de tradução é consequência do não reconhecimento da releitura que o trecho transferido pelo sistema exige desse profissional, seu trabalho de adequação do segmento recuperado ao novo contexto e a reconstrução que efetua do sentido geral da tradução. Essa atitude também reflete a ideia de que o tradutor seria unicamente responsável pela adequação dos segmentos estáveis e anteriormente traduzidos em novos contextos, limitando ao máximo sua interferência, como também pela produção de novas traduções que, armazenadas na memória do sistema com seus correspondentes linguísticos, gerariam novas possibilidades de tradução em trabalhos posteriores.

Por esse prisma, a noção de língua como um simples instrumento parece associar-se à ideia da possibilidade de correspondência biunívoca entre línguas, argumento esse evidenciado pela própria maneira como os sistemas de memória pareiam e mantêm armazenados trechos da tradução e do respectivo original para consulta e reaproveitamento posteriores. Traduzir, de acordo com essa configuração, envolveria basicamente recuperar os significados assim mantidos nos bancos terminológicos dos sistemas de memórias e transportá-los para outros textos/contextos.

Vislumbrar a possibilidade de prever e dominar o trabalho de tradução, contendo o uso da língua na produção do texto de origem e empregando os recursos das memórias para padronizar a terminologia e fraseologia adotada, representa, por fim, uma tentativa de controlar as diferenças entre as línguas. Ao tradutor, caberia traduzir somente as ocorrências em que o sistema não tenha encontrado correspondência em sua memória.

Por outro lado, ferramentas como os sistemas de memórias não oferecem atalhos aos inevitáveis problemas e desafios com que o tradutor se depara em seu trabalho, os quais acabam sendo subestimados, dado o enfoque na aplicação dos recursos de recuperação de traduções anteriores de que dispõem os sistemas de memórias.

\section{CONSIDERAÇÕES FINAIS}

As novas relações linguísticas estabelecidas com a expansão da comunicação pela internet têm afetado a prática de tradução na contemporaneidade. O foco desse setor em resultados imediatos e a priorização da rapidez de produção condicionam a contratação do tradutor ao emprego e ao domínio dos recursos oferecidos por ferramentas como os sistemas de memórias que, idealmente, lhe possibilitariam 
aumentar sua produtividade e alcançar a padronização terminológica e fraseológica de traduções.

Esse tipo de estratégia tem sido majoritariamente empregado na composição de textos em inglês, língua de origem de grande parte dos materiais textuais submetidos a projetos multilíngues para circulação na internet, que partem de um único texto para a tradução para as diversas línguas em que esse conteúdo será divulgado. Essa maneira de trabalhar com textos reflete a crença na neutralidade da língua e retoma a visão comumente a ela atribuída como instrumento de comunicação e, em particular no caso da tradução, um meio "neutro" de transmissão de segmentos textuais entre diferentes línguas. Como discutido neste trabalho, a crescente dissociação entre a língua inglesa e sua cultura de origem serve como evidência dessa concepção contemporânea de tradução.

\section{AGRADECIMENTO}

Agradeço à FAPESP pelos recursos da bolsa de doutorado (processo no. 06/609745) que possibilitaram a pesquisa para elaboração deste artigo.

\section{REFERÊNCIAS BIBLIOGRÁFICAS}

BIAU GIL, J. R.; PYM, A. (2006) Technology and translation (a pedagogical overview). In: PYM, A., A., PEREKRESTENKO, A., STARINK, B. Translation technology and its teaching. Tarragona, Espanha. Disponível em <http://isg.urv.es/publicity/isg/ publications/technology_2006/index.htm>. Acesso em: 22 jun. 2006.

BOWKER, L. (2002) Computer-aided translation: a practical introduction. Ottawa: Ottawa University Press.

CALVET, L.J. (2007) As políticas linguísticas. Trad. Isabel de Oliveira Duarte; Jonas Tenfen; Marcos Bagno. São Paulo: Parábola Editorial: IPOL.

CRONIN, M. (2003) Translation and globalization. London: Routledge.

GRADDOL, D. (1997) The future of English? London: British Council.

. (2003) The decline of the native speaker. In: ANDERMAN, Gunilla, ROGERS, Margaret (Ed.). Translation today: trends and perspectives. Clevedon: Multilingual Matters. p. 152-167.

. (2006) English next. London: British Council. Disponível em: <www.britishcouncil. org/learning-english-next.pdf > . Acesso em: 15 maio 2008.

LE BRETON, J. M. (2005) Reflexões anglófilas sobre a geopolítica do inglês. In: LACOSTE, Yves; RAJAGOPALAN, Kanavillil (Org.). A geopolitica do inglês. São Paulo: Parábola Editorial. p. 12-26. 
RAJAGOPALAN, K. (2005) A geopolítica da língua inglesa e seus reflexos no Brasil. In: LACOSTE, Yves; RAJAGOPALAN, Kanavillil (Org.). A geopolítica do inglês. São Paulo: Parábola Editorial. p. 135-157.

WEININGER, M. (2004) TM \& MT tradução técnica globalizada - tendências e consequências. Cadernos de Tradução, Florianópolis, v. 2, n. 14, p. 243-263.

WODAK, R. (2004) Políticas linguísticas europeias: tensões devidas à globalização e ao nacionalismo. In: SILVA, F. L.; RAJAGOPALAN, K. (Org.). A linguística que nos faz falhar: investigação crítica. São Paulo: Parábola Editorial. p. 145-152.

Recebido: 05/05/2011

Aceito: 09/11/2011 